\title{
Developed Web-based System for Performance Evaluation based on Balanced Scorecard Model: Case Study in Ethiopian Organizations
}

\author{
WORKU MEKONNEN TESSEMA
}

Computer Information System, Near East University, TRNC, Nicosia, Cyprus.

\begin{abstract}
In this research a developed web-based balanced scorecard performance evaluation system proposed for the case study of Ethiopian organizations and supports both English and Amharic languages. The system incorporates evaluations of individual performance (both in activity and behavior), major activity performance, objective performance, perspective performance, unit/ department performance, and the organization/institute as a whole based on time, cost, quality and quantity. Object oriented software engineering and ASP.NET 4.0 platform is employed to develop the system. Reviewing the overall results from the usability test, questionnaires and interviews, it is concluded that all production and extensive public service providing organizations prefer to use the implemented application but other organizations comparatively didn't want to use it as it seems it doesn't facilitate their daily duties. But the overall functionality of the system is being agreed by the users.
\end{abstract}

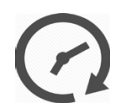

Article History

Received: 08 October 2018 Accepted: 28 December 2018

\section{Keywords}

Balanced Scorecard, Performance Evaluation, Balanced Scorecard-Based Management System.

\section{Introduction}

Performance measurement has great impact in organization management procedure. The need to impressive performance tools to produce evaluation reports for business performance grounded on commercial as well as non-commercial measures increased in recent years. ${ }^{1}$ The balanced score card (BSC) system proposed by Robert Kaplan and David Norton in 1992 as" an execution estimation system that additional vital non-money related execution measures to customary budgetary measurements gives chiefs and officials a more 'adjusted' perspective of authoritative execution". ${ }^{2}$ It provides comprehensive tactical performance metric framework applied widely in industry, government, and non-commercial organizations. ${ }^{2}$

Considering weak points and ambiguity of previous management models, The BSC system offers a clear prescription to the factors that organizations must

CONTACT Worku Mekonnen Tessema $\$ workumt@gmail.com 9 Computer Information System, Near East University, TRNC, Nicosia, Cyprus.

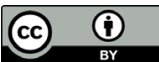

(c) 2018 The Author(s). Published by Oriental Scientific Publishing Company

This is an $\partial$ Open Access article licensed under a Creative Commons license: Attribution 4.0 International (CC-BY).

Doi: http://dx.doi.org/10.13005/ojcst11.04.07 
estimate to apply qualified evaluation metrics for both internal and external communication in business perception, and advance monitoring techniques to achieve the organization strategic plans. ${ }^{3}$

In traditional systems, the implementation of behaviour control evaluation tools of past performance aimed to preserve individual entities and organization units in agreement with a pre-defined strategy. The evaluation procedures on BSC system handled by managers in altered approach that managed to fluent the business scheme, to connect the strategy of organization and to support individual, organizational, and cross-functional enterprises to succeed. For successful implementation of BSC, Perfect illustration of the organizations long-term plan is needed. ${ }^{4}$

Today, most Ethiopian organizations, the case study of this research, adopt the BSC management model for most of government organizations. BSC impact in Ethiopian organizations management addressed in several researches. Tilaye Kassahun. ${ }^{5}$ Study depended on meta-examination of existing BSC-related writing in business and missiondriven associations over the globe with an aim of benchmarking the accepted procedures in the zone. A far reaching examination and union of a surviving writing brought about an engineering outline of BSC for academic foundations working in Ethiopia. For his study about commercial banks and BSC system implementation, Mitiku Regasa ${ }^{6}$ research's analysis and results returned main accomplishments and challenges, approach of teams and management obligations concerning Balanced Score Card and its effect. The study adopted that BSC increased sufficiently multiple profits due to BSC employment in commercial bank sector. The fact is that BSC management system considered being a developing sector for many reasons such as financial stress, inadequate resources, low spending budgets, as well as innovative governmental rules. As a result, there is a need to evaluate performances of individuals, activities and hence organizations. According to the literature, a variety of researches about performance evaluation systems conducted in different countries. None of them include personal behavior evaluation. However, there is no performance system that uses both Amharic and English best of the researcher knowledge. In these endeavors it has been observed that most of the daily operations including performance evaluation in a balanced scorecard tool are not captured and processed in a systematic and automated way to support the organizational operations and to rank and promote best performers. This absence is manifested as:

- Lack of getting the right performance information, particularly individual performance result, to the precise people at the accurate period for both ranking and promoting;

- Absence of efficient complex information analysis report tools to corporate data from different resources ,since they may need gathering from different sheets of data;

- Unreliability and insecurity of communications performance information;

- $\quad$ Lack of quick access to actual performance data to make better decisions; and

- Lack of integrations within different organizational units.

Due to the aforementioned problems, main objective of this research work is to develop a web based performance evaluation of organizations and individuals/civil servants that helps the implementation of balanced scorecards in the context of Ethiopia that is capable of fitting into an Enterprise Resource Planning /ERP/ system of organizations. Subsequent goals include,

- Study and analyse the current/existing/ manual system of balanced scorecard performance evaluation for some selected organizations in Ethiopia,

- $\quad$ Determine the thresholds and measurements of the perspectives, goals/objectives, and major activities of organizations automatically,

- Measure and evaluate the perspectives, objectives, major activities, individuals and hence institutions according to the planned measures.

Balanced Scorecard and the Developed Software Balanced scorecard is a method for estimating managerial, business entity or department achievement; adjusting long and short period plans in relevant to immediate activities and balancing distinctive measures of progress. ${ }^{9}$ The key perspectives of the BSC concentrate into four central perspectives ${ }^{9}$ :

- $\quad$ Customer: Incorporates events as customer 
approval, customer preservation, new customer reply period, marketplace, and customer viability.

- $\quad$ Financial: Comprises productivity measures such as effective profits, trades progress, currency generation, or financial worth added.

- Internal process: Consists of metrics for product plan, product progress post-sale service, industrial competence, product quality.

- Human resource and growth: consists of estimations of representatives' capacity, data courses of action, and authoritative measures to accomplish the business and adjust to alteration.

The basic destinations of execution assessment structure are to give a reasonable estimation of an agent's sense of duty regarding the workforce, convey exact assessment documentation to guarantee both the business and association rights, and get an irregular condition of significant worth and sum in the work made.

Balanced score card (BSC) as a model of performance, is effective in that "it articulates the links between leading inputs (human and physical), processes, and lagging outcomes and focuses on the importance of managing these components to achieve the organizations' strategies priorities". ${ }^{10}$

Organization extensive application of a BSC needs more automated support tools. According to the survey conducted in this research work, Ethiopian organizations use Microsoft Excel to motivate BSC performance evaluation. Utilizing spread sheet reports to help the usage of BSC has numerous detriments, for example, limitation in number of sheets could be used, more time expending to update, lack of support for cooperative and communication tools, poor analysis methodology. ${ }^{7}$

Developed software programs used to help a BSC occupation in management for some reasons, consequently they coordinates information from dissimilar information sources, permits extensive information analysis, and encourages communication tools for BSC evaluation enhancement. ${ }^{8}$ Organization management based on BSC system need to identify their strategy plan. Then mangers shall choose the appropriate software tool which required important features to support financial and non-financial reports occupied with evaluation performance of activities and individuals. Choosing the unsuitable software tool can undermine the whole BSC improvement exertion and the validity of the performance management framework.

The developed system produced in this research should be the best fit BSC software for Ethiopian organizations since it developed after a deep study of the related organizations requirements and management strategy.

\section{Material and Methods}

In order to conduct the research, the following activities fulfilled:

- $\quad$ The case study for the developed system considered some Ethiopian organizations that adopt the BSC model as performance evaluation strategy, which covered the Ethiopian Document Authentication and Registration Office /DARO/, Center for Educational ICT, and Kality Metal Factory. In order to develop the system, object oriented software engineering model used, which consists of requirement elicitation and analysis, system and object design, implementation and testing phases. ${ }^{7}$

- Through the requirements analysis of the developed system, during data collection, three interviews with open-ended and four close-ended parties made, and two document review methods employed. Considering a stratified sampling technique, the collected data analyzed to produce a model of the anticipated system that is correct, complete, consistent, unambiguous, realistic, and verifiable.

Usability test made upon develop completion, the system installed in the chosen organizations and 15 questionnaires are made to conduct for the three organizations and given to 10 experts of each organizations to evaluate the developed system performance in sector of organizational and individual performance measurements.

- $\quad$ The research applied 30 participants who are selected purposefully, data are collected, analysed and implemented. 


\section{Developed Web-Based System \\ Programming}

To realize the feasibility and validity of the proposed solution, attributes and methods of the identified objects are converted to a source code and integrated in such a way that they work together for common purpose. This process fills the gap between the analysis model and the anticipated application.

To develop the prototype which can meet the design goals of Balanced Scorecard Management system (BSCMS), different tools and platforms have been used. The Microsoft ASP.NET 4.0 platform is used, and consists of the following.

- Microsoft Visual Web Developer 2010 Express Edition Integrated Development Environment

- $\quad$ C\# programming language

- $\quad$ Microsoft SQL Server 2008 Express Edition

- $\quad$ DevXpress 2010

\section{System Analysis and Design}

Requirement elicitation is done to identify the specific requirement for the Ethiopian context. To identify the requirements, interview and document review has been conducted with the chosen governmental organizations (those are selected since they are implementing BSC as strategic priorities) such as Document Authentication and Registration Office, Center for Educational ICT and Kality Metal Factory. The organizations have recently established reform offices which are delegated for initiation of balanced scorecard based performance evaluation system and developed manual evaluation system. The requirement elicitation has also showed that the organizations don't have as such a well-studied anticipated output.

Considering the result of requirement elicitation, standard of vital activity evaluation systems, the context of the country, and anticipation of customers, requirements of the proposed system are set.

\section{Functional Requirements}

Functional requirements portray the associations between the framework and its condition free of its usage. The earth incorporates the client and some other outside framework with which the framework communicates. Along these lines, the major utilitarian necessities of this study include:
- $\quad$ The system should allow the user to register perspectives, objectives, annual activities, sub-activities;

- $\quad$ The system should be able to evaluate each activity, objective, employee;

- $\quad$ The system should allow the user to approve activities planned and accomplishment performed;

- $\quad$ The system should allow the user to cascade perspectives, objectives and annual activities;

- The system should allow the user to rank and select best performers, activities, objectives, perspectives, and departments /units;

- $\quad$ The system should be able to generate various reports of activities such as weekly, monthly, quarterly, bi-annual, annual, and behavior report;

- $\quad$ The system should provide different levels of privileges to users to manipulate the records; The system should operate both in Amharic and English languages; and

- $\quad$ The system should be able to authenticate and authorize users.

\section{System Models}

Use cases are utilized amid prerequisites elicitation and investigation to speak to the usefulness of the proposed framework. Utilize cases center around the conduct of the framework from an outside perspective. An utilization case is utilized to portray a capacity gave by the framework that yields a noticeable outcome for a performer. An on-screen character depicts any element that cooperates with the framework, for example, a client, another framework. The performers are outside the limit of the framework, though the utilization cases are inside the limit of the framework. The following use cases and actors are identified for the proposed system called Balanced Scorecard-based Management System for Performance Evaluation /BSCMS/. Use case diagram of BSCMS is shown in Appendix A.

\section{System Architecture}

Considering the characteristics of the application anticipated by the client, the system is designed to have three-tiered centralized client/server architecture. Following layered architectural style, the system will have the user interface (UI) level, the preparing level and the information level. The UI layer contains all that is important to straightforwardly 
interface with the client, for example, show administration. The center level regularly contains the handling rationale. At long last at the base, the information level, really deals with the information that is being followed up on. The proposed framework design is appeared in UI level, the preparing level and the information level. The UI layer contains all that is important to specifically interface with the client, for example, show administration. The center level regularly contains the handling rationale. At long last at the base, the information level, really deals with the information that is being followed up on. The proposed framework design is appeared in Figure 1

\section{Algorithm of Evaluation}

This component sets the evaluation criteria and type of behaviour evaluation of an individual, and then evaluates objectives, activities, and individuals' behaviour based on the given criteria. The algorithm which is developed /created by the authors for evaluation component is given below.

The behavior evaluation criteria and type has to be created first

The year, evaluation period, criteria, and type is selected
Register behavior evaluation

If Registered Behavior evaluation is updated

Update Behavior evaluation

Behavior criteria, type, and year enabled is True

Else

If check behavior is true

This behavior is already registered

Else

Register behavior evaluation

Behavior evaluation registered successfully and submitted

Behavior evaluation.DataBind ();

If behavior evaluation has value (i.e $>=0$ )

Evaluation Type .value $=$ Behavior Evaluation . GetdataRaw(type)

Criteria.value $=$ Behavior Evaluation . GetdataRaw(criteria)

Rank.value $=$ Behavior Evaluation GetdataRaw (rank)

Evaluation year.value $=$ Behavior Evaluation . GetdataRaw(year)

RegisterBehavior Evaluation. Text= 'Update'

Behavior criteria, year, type enabled is False

Else

Select value from the list.

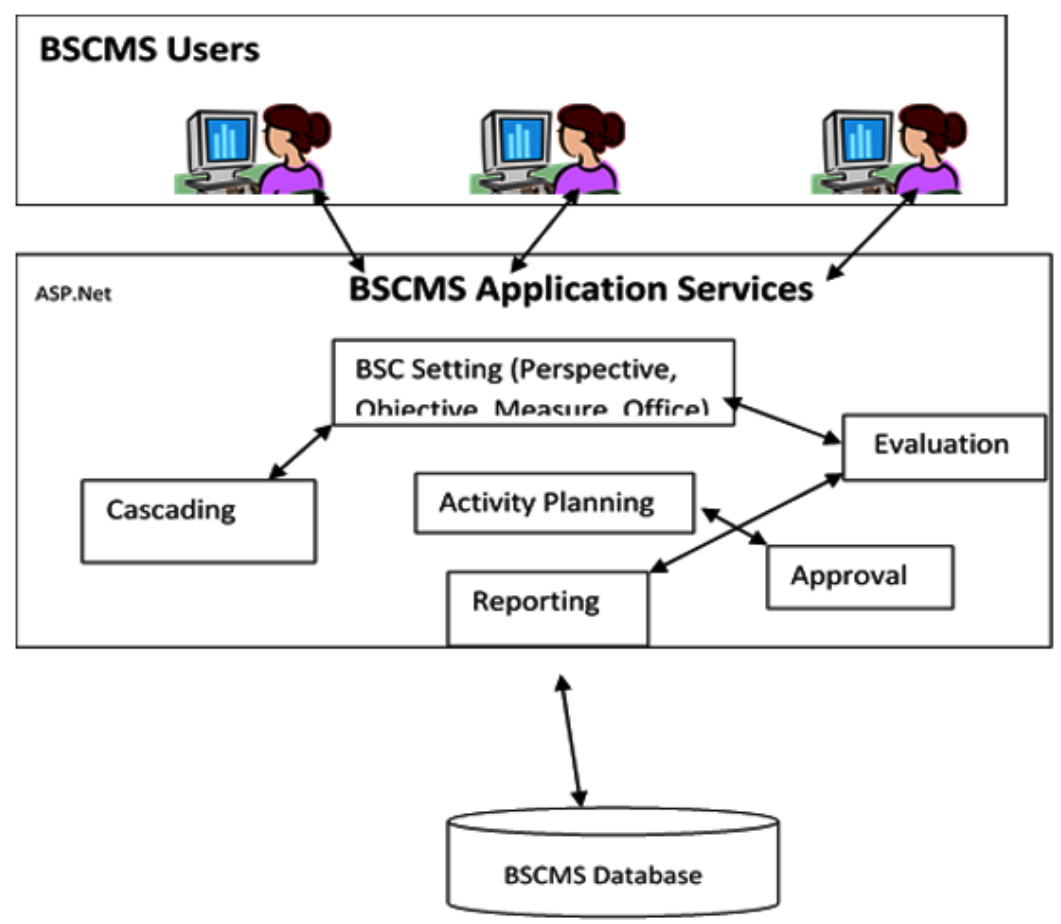

Fig. 1: System Architecture of the Developed System 


\section{Main Process of the System}

- Office Setting: This component is responsible to register Institute/Organization, Office and Sub-office or Departments, Positions under the institute, and Office Category to which the offices are categorized as Administrative, Academic or others. Screenshot of Office Setting page is shown in Figure 2.

- $\quad$ Report: This component is used to generate the reports of performances at different levels such as individual behaviour, activities, objectives, perspectives, measurement accomplishment, etc. Weekly, monthly, quarterly, bi-annually, and annually. Screenshot of sample reports of only weekly and monthly activities are shown in Figure 3.

\section{Results and Discussion}

We conducted usability tests to evaluate the BSCMS interfaces and its functionalities. This study explores and maps experiences regarding the interaction of

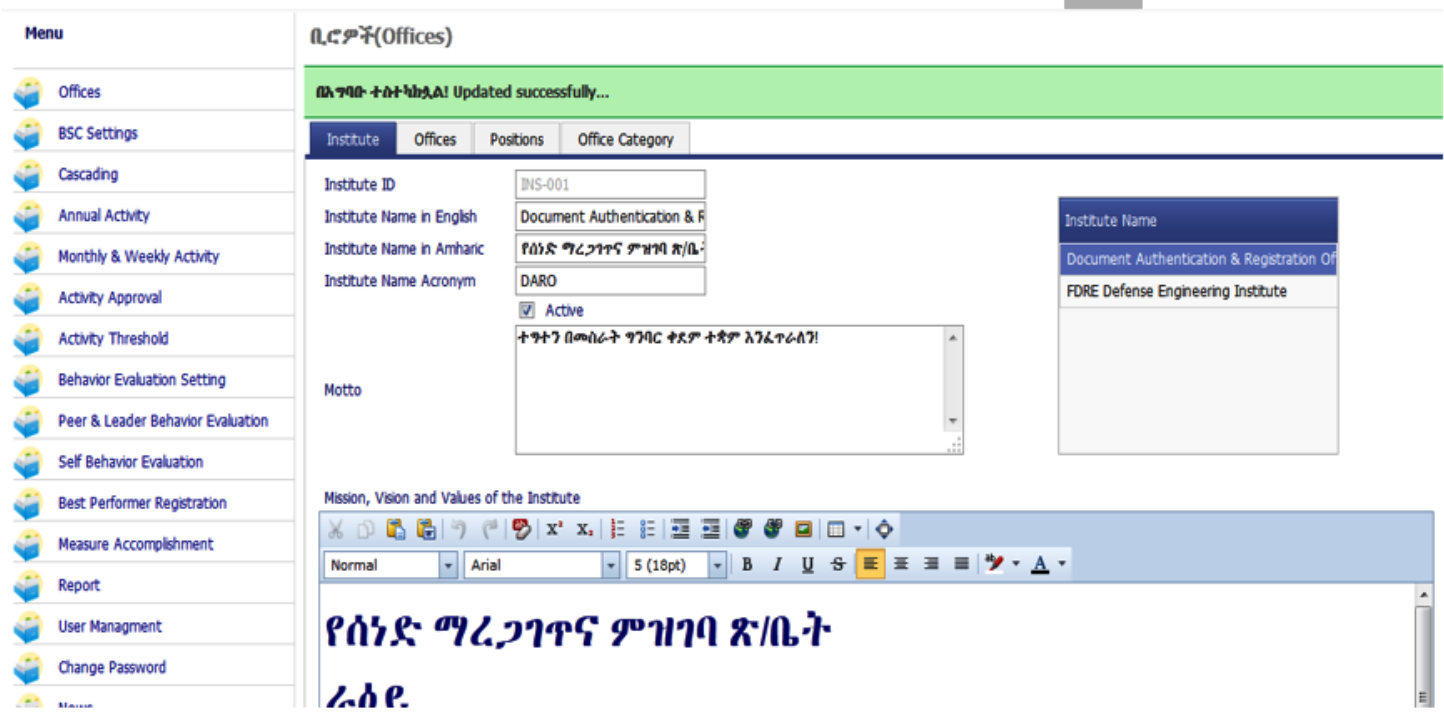

Fig. 2: Screenshot of Office Setting Page

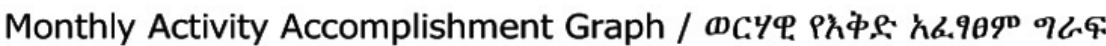

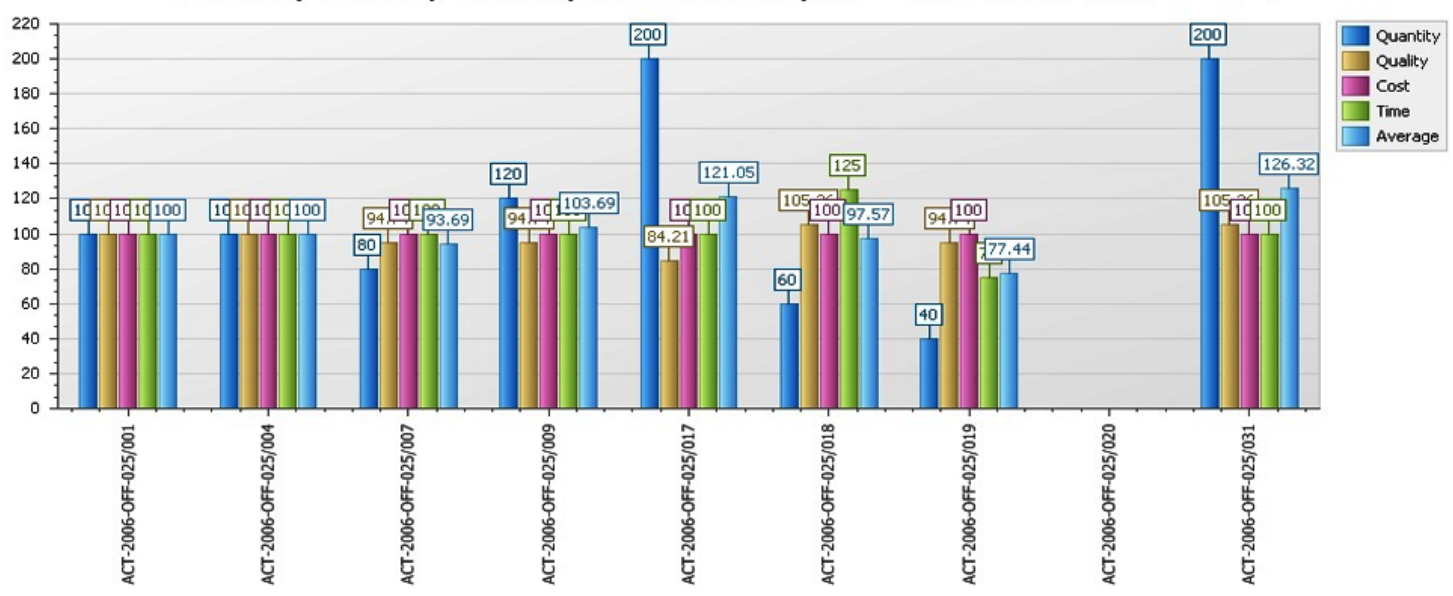

Fig. 3 (a): Screenshot of different types of reports page a) Monthly Accomplish graph 


\begin{tabular}{|c|c|c|c|c|c|c|c|c|c|c|c|c|c|c|}
\hline Strategic Year $P \lambda \phi \& q 00+$ : & & & [onth/ $\omega C: J$ & July/ $\mathrm{k}$ & H97n & & & & & & & & & \\
\hline 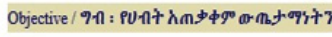 & 7 वृभTa & & & & & & & & & & & & & \\
\hline & & & Plan / $\lambda \dot{\beta}$ & & & Accomp & aplishmen & ent $/ \lambda \boldsymbol{\alpha}$ ? & $.990^{\circ}$ & Accompl & plishment & at in $\% / \lambda$ & $\lambda<9890$ & 00m $\$ 5$ \\
\hline Activity $\varphi S+ๆ \Upsilon C$ & $\begin{array}{l}\text { Quartiy/, } \\
\operatorname{lom}_{m} 3\end{array}$ & Unt/ oriths & Quality / & $\begin{array}{l}\text { Cost/ } \\
\text { noman }\end{array}$ & $\begin{array}{l}\text { Time/ Unit/ } \\
\text { nz, ooshs }\end{array}$ & $\begin{array}{l}\text { Quartity/ } \\
\ln m \mathrm{~m} 3\end{array}$ & $\begin{array}{l}\text { Quality / } \\
\text { nTLt }\end{array}$ & Cost/ & $\begin{array}{l}\text { Tme/ } \\
\mathrm{ALH},\end{array}$ & $\begin{array}{l}\text { Quantity/ } Q \\
\text { alomis }\end{array}$ & $\begin{array}{l}\text { Quality / } \\
\text { arct }\end{array}$ & Cost & $\begin{array}{l}\text { Timel } \\
\text { azis }\end{array}$ & $\begin{array}{l}\text { Average/ } \\
\lambda \text { The }\end{array}$ \\
\hline 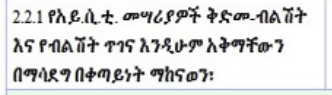 & 5 & Percent & 95 & 100 & $2 \begin{array}{l}\text { Weet/s/ } \\
i g r z+\end{array}$ & 10 & 80 & 100 & 2 & 200.00 & 84.21 & 100.00 & 100.00 & 121.05 \\
\hline & & & & & & & & & & & 84.21 & 100.0 & 100.00 & 121.05 \\
\hline 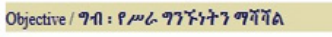 & & & & & & & & & & & & & & \\
\hline & & & $\mathrm{Plan} / \mathrm{\lambda} \boldsymbol{\mathrm { P } S}$ & & & Accom & aplishment & :nt $/ \lambda<9$ & . & Accompl & plishment & at in $\% / \lambda$ & 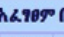 & 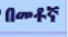 \\
\hline Activity $\varphi$ $+\eta\urcorner C$ & $\begin{array}{l}\text { Quartity/, } \\
\text { nosm? }\end{array}$ & Unt/ oroins & $\begin{array}{l}\text { Quality / } \\
\text { nTLt }\end{array}$ & Cost/ & $\begin{array}{l}\text { Time/ Unit/ } \\
\text { az,16 oonhs }\end{array}$ & $\begin{array}{l}\text { Quartity/ } \\
\text { norm? }\end{array}$ & $\begin{array}{l}\text { Quality / } \\
\text { nTht }\end{array}$ & Cost/ & $\begin{array}{l}\text { Time/ } \\
\text { n2,H }\end{array}$ & $\begin{array}{l}\text { Quantity/ } \\
\text { noman? }\end{array}$ & $\begin{array}{l}\text { Quality / } \\
\text { arLt }\end{array}$ & Cost & $\begin{array}{l}\text { Time/ } \\
\text { azie }\end{array}$ & $\begin{array}{l}\text { Average/ } \\
\lambda \text { \%भg, }\end{array}$ \\
\hline 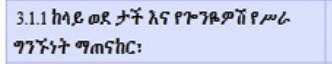 & 5 & Percent & 95 & 100 & ${ }^{2}$ Week/s/ & 3 & 100 & 100 & 1.5 & 60.00 & 105.26 & 100.00 & 125.00 & 97.57 \\
\hline 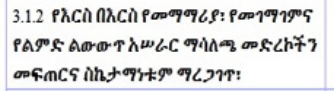 & 5 & Percent & 95 & 100 & 2 Weeks/s & 2 & 90 & 100 & 2.5 & 40.00 & 94.74 & 100.00 & 75.00 & 77.44 \\
\hline 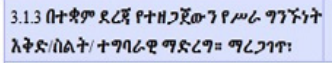 & 5 & Percent & 95 & 100 & $2 \underset{4907+}{\text { Week/s/ }}$ & & & & & .00 & .00 & .00 & .00 & .00 \\
\hline & & & & & & & & & & 3333 & 66.67 & 66.67 & 66.67 & 58.34 \\
\hline
\end{tabular}

Fig. 3 (b): Screenshot of different types of reports page b)monthly accomplish table

end users with the system interfaces. By observing end user's experiences we have analysed results and based on these offer recommendations to improve the usability of the application. Questionnaire is an inquiry approach which we have chosen to use for interface and functionality evaluation, as a way to gather more data from users. We designed simple and unambiguous questions that helped the users to answer these questions without difficulty. We used close-ended questions (15) in the questionnaire because it saves time to complete the questionnaire. (Appendix B)

In the prototype evaluation, three different organizations (CEICT, DARO, and KMF) were involved. We have used random sampling technique to select representative number of participants. The participants were chosen considering their knowledge of the basics of computer and positions they have. We have used 10 experts for each of the three selected organizations. Before conducting the evaluation process, detailed description about the prototype has been given to the participants as it helps them in having an insight to the system. After the demonstration of the prototype, participants were provided with respective questionnaires. A five level likert scale (strongly agree (5), agree (4), less agree (3), disagree (2) and strictly disagree (1) is used for the responses of the questions because it is easy to interpret.
The 15 questionnaires were distributed among the users in the form of hard copies to the three organizations. The questionnaire was handed for 8 hours out to all 30 participants from the three organizations after using the system. The questionnaires were used to capture their sense of satisfaction concerning the application developed. The designed questionnaire can be found in Appendix B.

After getting response from users through the questionnaire, we calculated each scale of questionnaire. The Table shown in Appendix C summarizes the respondents' result of the system questionnaire of each question in number for the three organizations. According to the respondent, the BSCMS prototype is clear, clean, and attractive screen design. As the result shows in the Table shown in Appendix C, questions 1 to 10 of the questionnaire which are related to the design, organization, presentation of information, steps to accomplish a given task, easiness of the prototype and menu item consistency showed that most of respondents (74.5\%) agree and strongly agree for all selected organizations; $20.5 \%$ of respondents responds less agree and only very few (5\%) responds disagree and strongly disagree. Questions 11 to 15 of the questionnaire which are related to the basic functionalities of the BSCMS such as 
Table 1: Analysis of degree usability testing to compare three organizations

\begin{tabular}{lcccccc}
\hline Answer & \multicolumn{2}{c}{ CEICT } & \multicolumn{2}{c}{ KMF } & \multicolumn{2}{c}{ DARO } \\
\hline & $\mathrm{N}$ & $\%$ & $\mathrm{~N}$ & $\%$ & $\mathrm{~N}$ & $\%$ \\
Strongly agree & 40 & 26.7 & 75 & 50 & 70 & 46.7 \\
Agree & 30 & 20 & 50 & 33.3 & 50 & 33.4 \\
Less Agree & 50 & 33.3 & 25 & 16.7 & 20 & 13.3 \\
Disagree & 25 & 16.7 & 0 & 0 & 10 & 6.6 \\
Strongly Disagree & 5 & 3.3 & 0 & 0 & 0 & 0 \\
Total & 150 & 100 & 150 & 100 & 150 & 100 \\
\hline
\end{tabular}

$\mathrm{N}=$ Number of occurrences for each degree on scale marked by users.

$\%=$ Percentages of each question answered

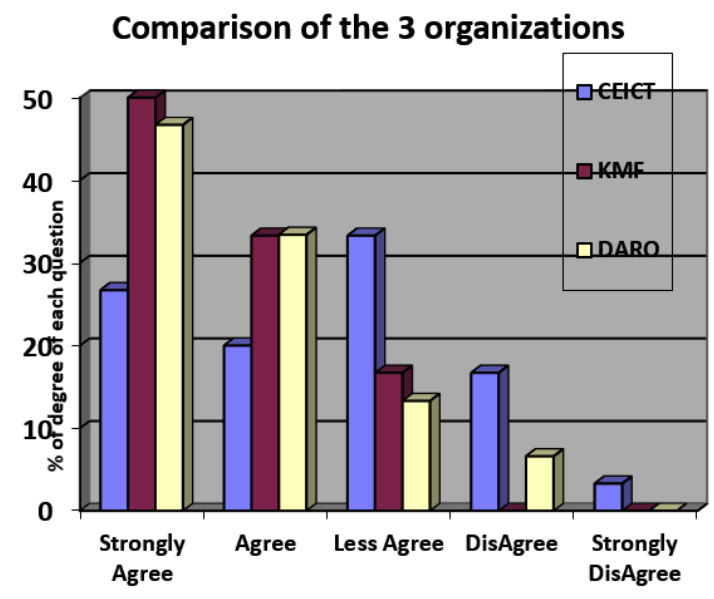

Fig. 4: Graphical Analyses of CEICT, KMF and DARO

evaluating performances of individuals' activities and behaviour, making easiness of daily duties showed that $51 \%$ responses agree and strongly agree; $26.5 \%$ responses less agree and $22.5 \%$ responses disagree and strongly disagree.

As shown in Table1 and Figure 4, we compare and analyse the three organizations from the questionnaire results that the percentage of strongly agree for CEICT, KMF and DARO was $26.7 \%, 50 \%$ and $46.7 \%$ respectively. $20 \%$ users were agree for CEICT, 33.3\% for KMF and $33.4 \%$ for DARO. 33.3\% of users were less agree for CEICT, $16.7 \%$ for KMF and $13.3 \%$ of users for DARO. Similarly $16.7 \%$ users were disagree for CEICT, $0 \%$ for $\mathrm{KMF}$ and $6.6 \%$ for DARO and $3.3 \%$ users were strongly disagree for CEICT and $0 \%$ for both KMF and DARO.

According to Table 1 and Figure 4, testing results show that the percentage of Strongly Agree and Agree was high for KMF and DARO while percentage of Less Agree, Disagree and Strongly Disagree was high for CEICT. It is worth mentioning here that "Strongly Agree" always positive and "Strongly Disagree" always negative concerning usability.

\section{Conclusions}

The current attitude of government and professionals on balanced scorecard based management is encouraging to take the advantages of the system. In this study we have analysed the standard, opportunities, experiences, and requirements on balanced scorecard based management systems of three organizations in Ethiopia.

Considering the specific needs and facts of the organizations, we have designed and implemented a bilingual Balanced Scorecard based Management system, which can handle activities' plans and accomplishments weekly, monthly, bi-annually, and annually; individuals' behaviour and activity performance evaluation; ranking best performers for promotions. The prototype is implemented and tested in three organizations i.e Center for Educational ICT, Document Authentication and Registration office, and Kality Metal Production. 
By reviewing the overall results from the usability test, questionnaires and interviews, we concluded that all production and extensive public service providing organizations prefer to use the implemented application but other organizations comparatively didn't want to use it as it seems it doesn't facilitate their daily duties. However, the application is preferred by most users specially directors and team leaders in terms of usability features because of its clean, easy to use, simple interface. Although BSCMS has many features, it could be possible to offer recommendations and to design more additional features and interfacing for the system that are easy to use, attractive and fulfil user's requirements.

\section{References}

1. Frigo, M.L. and Krumwiede, K.R., 1999. Balanced scorecards: a rising trend in strategic performance measyrement. Journal of strategic performance measurement, 3(1),pp.42-48.

2. Kaplan, R.S. and Norton, D.P., 2000. Putting the Balanced Scorecard to work, Focusing Your Organization on Strategy- with the Balanced Scorecard, 2, pp.2-18.

3. Hoque, Z. and James, W., 2000. Linking balanced scorecard measures to size and market factors: impact on organizational performance. Journal of management accounting research, 12(1), pp. 1-17.

4. Kaplan, R.S. and Norton, D.P., 1996. Linking the balanced scorecard to strategy, California management review, 39(1), pp.53-79.

5. Kassahun, T., 2010. Rethinking institutional excellence in Ethiopia: adapting and adopting the balanced scorecard (BSC) model. Journal of Business and Administrative Studies,2(1), pp.22-23
6. Regassa, M., 2015. The Practices and Challenges of Balanced Scorecard Implementation: A case of Commercial Bank of Ethiopia (Doctoral dissertation, St. Mary's University).

7. Marr, B. and Neely, A., 2001. Balanced Scorecard Software Report, Gartner Inc., Cranfield University.

8. Marr, B. and Neely, A., 2003. Automating the balanced scorecard- selection criteria to identify appropriate software application. Measuring Business Excellence, 7(3), pp.2936.

9. Kairu, E.W., Wafula, M.O., Okaka, O., Odera, O. and Akerele, E.K., 2013. Effects of balanced scorecard on performance of firms in the service sector: European Journal of Business and Management, 5(9), pp.81-88

10. Najafi L., et. al., Personnel Performance Evaluation based on Balanced Scorecard (BSC) in Iran Health Networks, Research Journal of Management Sciences Vol. 4(3), 1-5, March 2015. 


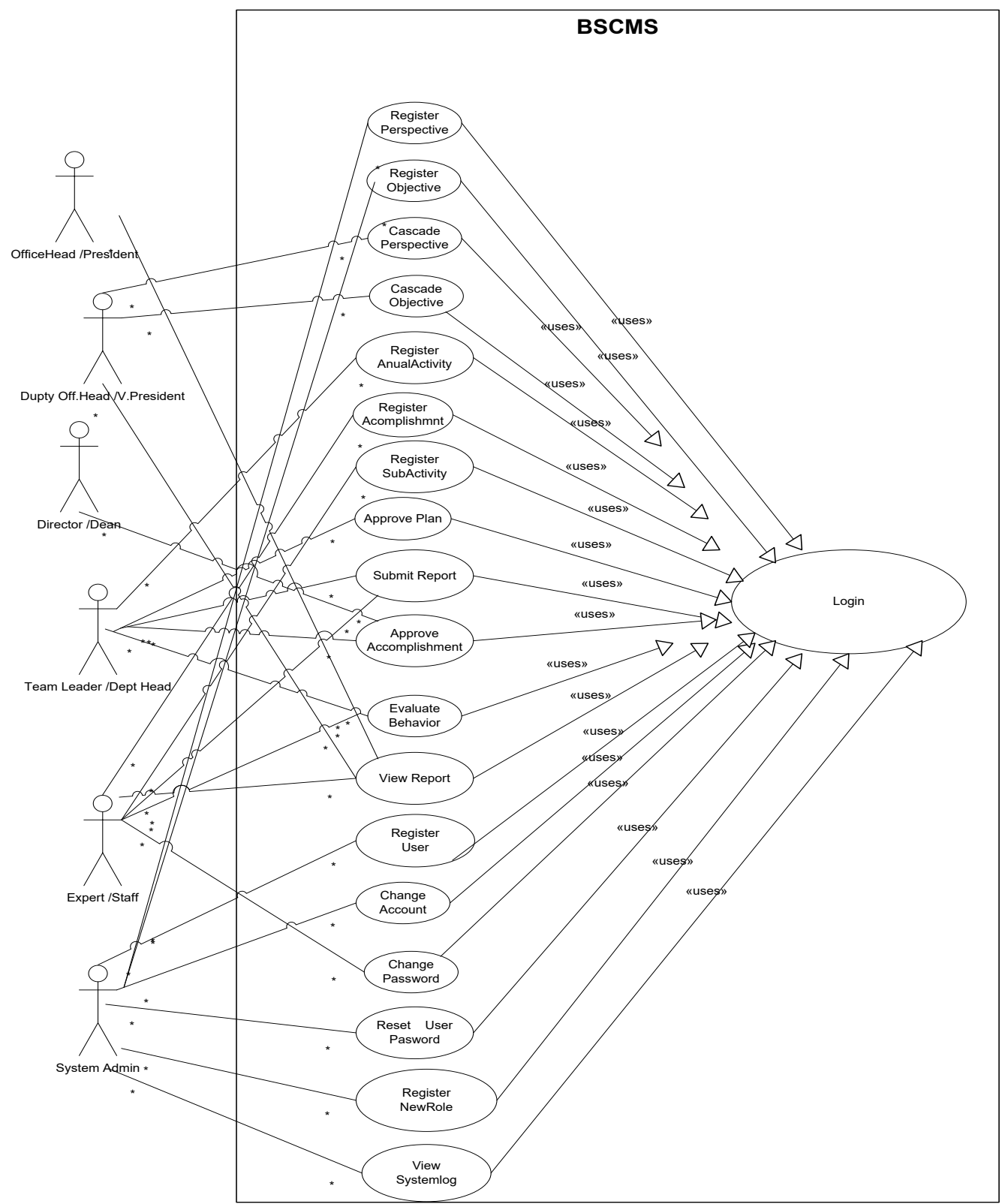

Appendix A: Use Case Diagram of BSCMS 
Appendix B: Questionnaire for Usability Test

\begin{tabular}{lll}
\hline No & Questionnaire for Usability Evaluation & Score \\
\hline & & 2 \\
1 & The system had a clear, clean, and attractive screen design & 5 \\
2 & The application minimized the number of steps it took to complete tasks & 3 \\
3 & Information presented on screens is easy to comprehend quickly \\
4 & The system provides appropriate information for users \\
5 & The system will increase users confidence and performance \\
6 & Choice lists are clear and unambiguous \\
7 & Information needed for a specific task is grouped together on a single screen \\
8 & The menu items were well organized and functions are easy to find. \\
9 & I immediately understood the function of each menu item. \\
10 & The system is complete enough to provide intended information \\
11 & The system makes easy my daily duty \\
12 & The system meets the overall required functionalities about performance evaluation \\
13 & The system incorporates all components of BCS in evaluating activities, plan, measures \\
14 & The system incorporates all components in evaluating individual behaviour \\
15 & The system responses is quick
\end{tabular}

Key:

$1=$ Strongly agree; $2=$ Agree $; 3=$ Less Agree; $4=$ Disagree; $5=$ Strongly Disagree

Appendix C: Detailed summary of questionnaire result

\begin{tabular}{|c|c|c|c|c|c|c|c|c|c|c|c|c|c|c|c|}
\hline \multicolumn{2}{|c|}{$\begin{array}{l}\text { Question } \\
\text { No. }\end{array}$} & \multicolumn{3}{|c|}{$\begin{array}{l}\text { Center for } \\
\text { Educational }\end{array}$} & \multicolumn{6}{|c|}{$\begin{array}{l}\text { ICTKality Metal } \\
\text { Factory }\end{array}$} & \multicolumn{5}{|c|}{$\begin{array}{l}\text { Document Authen. } \\
\text { \& Regst. Office }\end{array}$} \\
\hline & SA & $\mathrm{Ag}$ & LA & $\mathrm{Di}$ & SD & SA & $\mathrm{Ag}$ & LA & $\mathrm{Di}$ & SD & SA & $\mathrm{Ag}$ & LA & Di & SD \\
\hline 1 & 3 & 2 & 3 & 1 & 1 & 5 & 4 & 1 & 0 & 0 & 4 & 5 & 1 & 0 & 0 \\
\hline 2 & 3 & 2 & 3 & 1 & 1 & 5 & 4 & 1 & 0 & 0 & 5 & 3 & 2 & 0 & 0 \\
\hline 3 & 4 & 2 & 3 & 1 & 0 & 5 & 3 & 2 & 0 & 0 & 4 & 4 & 2 & 0 & 0 \\
\hline 4 & 3 & 2 & 3 & 1 & 1 & 5 & 3 & 2 & 0 & 0 & 5 & 3 & 2 & 0 & 0 \\
\hline 5 & 2 & 2 & 3 & 2 & 1 & 5 & 3 & 2 & 0 & 0 & 4 & 4 & 2 & 0 & 0 \\
\hline 6 & 3 & 3 & 3 & 1 & 0 & 5 & 3 & 2 & 0 & 0 & 5 & 3 & 1 & 1 & 0 \\
\hline 7 & 3 & 3 & 3 & 1 & 0 & 5 & 3 & 2 & 0 & 0 & 4 & 3 & 2 & 1 & 0 \\
\hline 8 & 3 & 3 & 3 & 1 & 0 & 5 & 3 & 2 & 0 & 0 & 5 & 3 & 1 & 1 & 0 \\
\hline 9 & 3 & 3 & 3 & 1 & 0 & 4 & 3 & 2 & 0 & 0 & 4 & 3 & 2 & 1 & 0 \\
\hline 10 & 3 & 3 & 2 & 2 & 1 & 4 & 3 & 2 & 0 & 0 & 5 & 2 & 2 & 1 & 0 \\
\hline 11 & 2 & 1 & 4 & 2 & 1 & 4 & 3 & 2 & 0 & 0 & 4 & 3 & 2 & 1 & 0 \\
\hline 12 & 2 & 1 & 4 & 2 & 1 & 4 & 3 & 1 & 1 & 0 & 5 & 2 & 2 & 1 & 0 \\
\hline 13 & 2 & 1 & 4 & 2 & 1 & 4 & 3 & 2 & 0 & 0 & 4 & 3 & 2 & 1 & 0 \\
\hline 14 & 2 & 1 & 4 & 2 & 1 & 4 & 3 & 2 & 0 & 0 & 4 & 3 & 2 & 1 & 0 \\
\hline 15 & 2 & 1 & 4 & 2 & 1 & 5 & 3 & 2 & 0 & 0 & 5 & 3 & 1 & 1 & 0 \\
\hline
\end{tabular}

